BNL-80018-2008-CP

\title{
The polarized SRF gun experiment
}

\author{
J. Kewisch ${ }^{\mathrm{a}}$, I. Ben-Zvi ${ }^{\mathrm{a}}$, T. Rao ${ }^{\mathrm{a}}$, A. Burrill ${ }^{\mathrm{a}}$, D. Pate ${ }^{\mathrm{a}}$, R. Grover ${ }^{\mathrm{a}}$, \\ R. Todd ${ }^{b}$, H. Bluem ${ }^{b}$, D. Holmes ${ }^{b}$, T. Schultheiss ${ }^{b}$ \\ a'Brookhaven National Laboratory, Upton, NY 11973 \\ ${ }^{\mathrm{b}}$ Advanced Energy Systems, Medford, NY 11763
}

Presented at PSTP2007: The International Workshop on Polarized Ion Sources, Targets, and Polarimetry

Brookhaven National Laboratory, Upton, NY

September 10-14, 2007

March 2008

\section{Collider-Accelerator Department}
P.O. Box 5000
Upton, NY 11973-5000
www.bnl.gov.

Brookhaven National Laboratory

\begin{abstract}
Notice: This manuscript has been authored by employees of Brookhaven Science Associates, LLC under Contract No. DE-AC02-98CH10886 with the U.S. Department of Energy. The publisher by accepting the manuscript for publication acknowledges that the United States Government retains a non-exclusive, paid-up, irrevocable, world-wide license to publish or reproduce the published form of this manuscript, or allow others to do so, for United States Government purposes.
\end{abstract}

This preprint is intended for publication in a journal or proceedings. Since changes may be made before publication, it may not be cited or reproduced without the author's permission. 


\section{DISCLAIMER}

This report was prepared as an account of work sponsored by an agency of the United States Government. Neither the United States Government nor any agency thereof, nor any of their employees, nor any of their contractors, subcontractors, or their employees, makes any warranty, express or implied, or assumes any legal liability or responsibility for the accuracy, completeness, or any third party's use or the results of such use of any information, apparatus, product, or process disclosed, or represents that its use would not infringe privately owned rights. Reference herein to any specific commercial product, process, or service by trade name, trademark, manufacturer, or otherwise, does not necessarily constitute or imply its endorsement, recommendation, or favoring by the United States Government or any agency thereof or its contractors or subcontractors. The views and opinions of authors expressed herein do not necessarily state or reflect those of the United States Government or any agency thereof. 


\title{
The Polarized SRF Gun Experiment
}

\author{
Jörg Kewisch ${ }^{\mathrm{a}}$, Ilan Ben-Zvi ${ }^{\mathrm{a}}$, Triveni Rao ${ }^{\mathrm{a}}$, Andrew Burrill ${ }^{\mathrm{a}}$, David Pate ${ }^{\mathrm{a}}$, \\ Ranjan Grover ${ }^{\mathrm{a}}$, Rob Todd ${ }^{\mathrm{b}}$ Hans Bluem ${ }^{\mathrm{b}}$, Doug Holmes ${ }^{\mathrm{b}}$ and Tom \\ Schultheiss ${ }^{\mathrm{b}}$ \\ ${ }^{a}$ Brookhaven National Laboratory, Upton, NY 11973 \\ ${ }^{b}$ Advanced Energy Systems, Medford, NY 11763
}

\begin{abstract}
RF electron guns are capable of producing electron bunches with high brightness, which outperform DC electron guns and may even be able to provide electron beams for the ILC without the need for a damping ring. However, all successful existing guns for polarized electrons are DC guns because the environment inside an RF gun is hostile to the GaAs cathode material necessary for polarization. While the typical vacuum pressure in a DC gun is better than $10^{-11}$ torr the vacuum in an RF gun is in the order of $10^{-9}$ torr. Experiments at BINP Novosibirsk show that this leads to strong ion back-bombardment and generation of dark currents, which destroy the GaAs cathode in a short time. The situation might be much more favorable in a (super-conducting) SRF gun. The cryogenic pumping of the gun cavity walls may make it possible to maintain a vacuum close to $10^{-12}$ torr, solving the problem of ion bombardment and dark currents. Of concern would be contamination of the gun cavity by evaporating cathode material. This report describes an experiment that Brookhaven National Laboratory (BNL) in collaboration with Advanced Energy Systems (AES) is conducting to answer these questions.
\end{abstract}

Keywords: Polarized Electron Beam Superconducting

PACS: 41.75.Fr 42.25.Ja

\section{INTRODUCTION}

In order to extract a polarized electron beam from a photo-cathode one has to be able to skim electrons with one spin direction from the lake of electrons in the cathode material. A Gallium-Arsenide (GaAs) cathode provides this possibility. By illuminating the cathode with circular polarized laser light, mostly electrons of one spin direction are lifted from the valence band into the conduction band due to the structure of the GaAs crystal. By using a "strained" crystal the number of electrons with the wrong spin direction can be minimized. This results in a maximum polarization degree of about $90 \%$. A mono-layer of Cesium on the cathode surface provides negative electron affinity which allows electrons in the conduction band to leave the cathode.

The problem with GaAs cathodes is the quantum efficiency lifetime which is shortened by ion back-bombardment. The accelerated electrons may hit and ionize a 
gas atom, and the ion will (because of the positive charge) be accelerated back towards the cathode.

The ion impact may damage the Cesium termination, which reduces the quantum efficiency of the cathode. It is therefore important to maintain a good vacuum inside the electron gun.

DC electron guns typically reach a vacuum of better than $10^{-11}$ torr [1], thus fulfilling this requirement. The vacuum of normal-conducting RF guns is only about $10^{-9}$ torr [2] because of the out-gassing due to the RF fields. It is still desirable to use RF guns because of the lower emittance of the electron beam and because a chopping system is not required in this case.

In the late 1990s Aleksandrov et al. [2] performed the first experiment of using a GaAs cathode inside an RF gun. The experiment used a 1/2-cell gun with an attached preparation chamber where the cathode could be moved to regenerate the GaAs surface. A pressure of $2 \cdot 10^{-10}$ torr was measured before RF was turned on. The pressure afterwards was not given in their papers. Due to both ion back-bombardment and electron bombardment, the quantum efficiency was only 10 seconds. They concluded however that a RF field of $30 \mathrm{MV} / \mathrm{m}$ does no irreversible damage.

In order to improve the vacuum level inside the gun, another experiment was performed at Fermilab [3] where a normal conducting RF gun was cooled with liquid nitrogen to cause cryo-pumping by the cavity walls. The experiment was partly successful. The pressure dropped when the gun was cooled, but only by a factor of two. The reason was that at $92^{\circ} \mathrm{K}$ only heavy gas molecules freeze to the walls.

To prove the effectiveness of cryo-pumping in an RF electron gun, it is therefore necessary to go to liquid helium temperatures. Brookhaven National Laboratory has two of the few super-conducting RF guns and is therefore capable of performing such an experiment as a step stone towards the use of SRF electron guns for polarized beams.

\section{THE EXPERIMENT}

We are using a $1.3 \mathrm{GHz} 1 / 2$-cell gun for the experiment. This gun will be installed in a 100 liter cryostat. The layout is shown in figure1.The gun is pointing upwards; a ceramic break in the beam pipe will allow measurement of the beam current. In order to maintain a vacuum of $10^{-11}$ torr when the gun is warm, a tank filled with getter pumps is part of the beam line. The beam is focused by a permanent magnet solenoid. This magnet will only limit the beam size and prevent beam loss in the beam pipe. The field is highly nonlinear, but for this experiment; we do not consider the beam emittance. The advantage of the permanent magnet is that it is not a heat source inside the helium.

The beam is leaving the cryostat through the top lid. It is then bent by a 90-degree magnet into a Faraday cup, where the current is measured. Two ports in the beam pipe 
allow shining the laser onto the cathode and the observation of the beam spot on the Faraday cup.

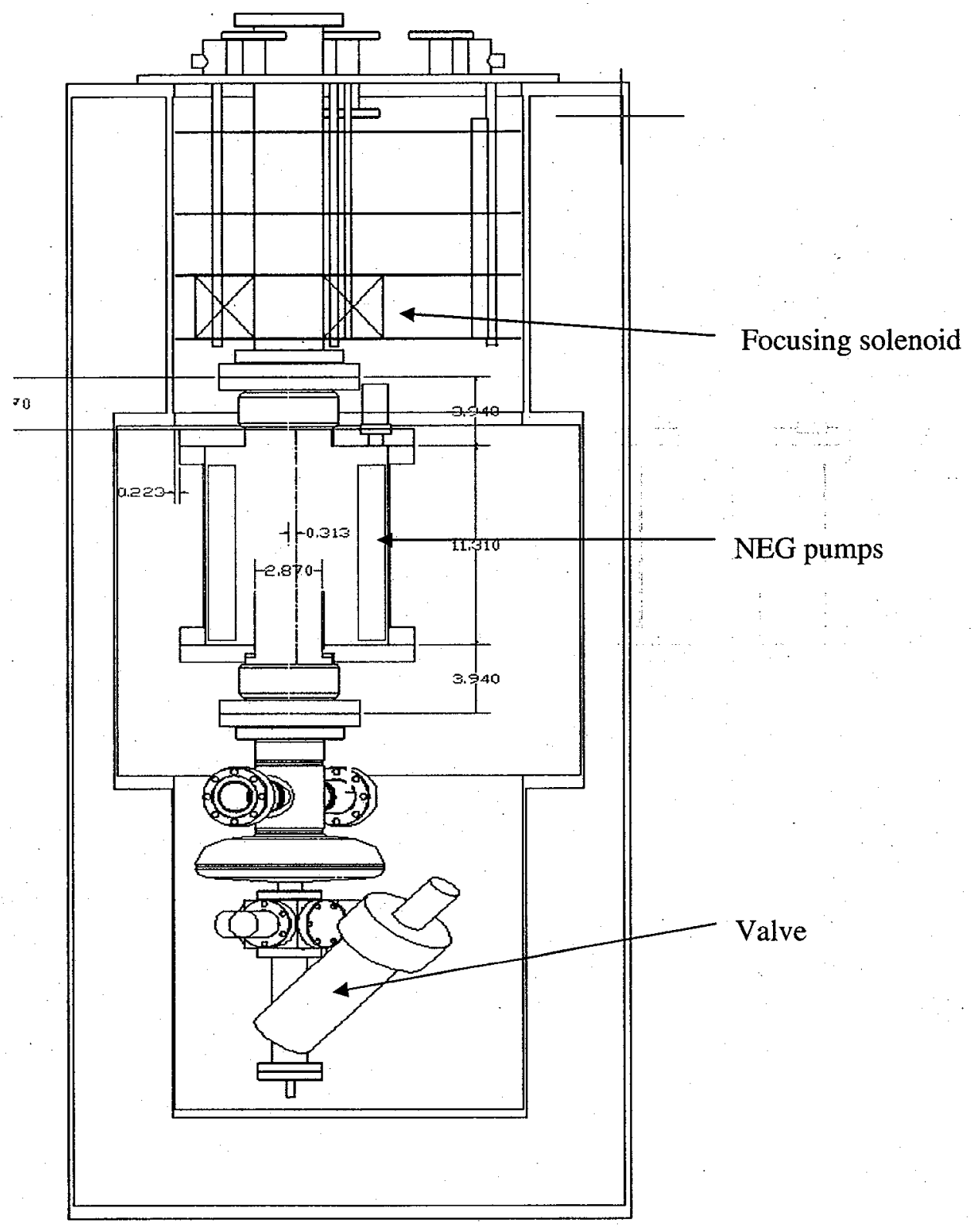

FIGURE 1. Positioning of the gun inside the cryostat.

In order to measure the cathode degradation due to ions and electrons it must be easy to regenerate the cathode material in a preparation chamber. Regeneration involves heating the cathode to up to $550^{\circ} \mathrm{F}$ and replenishing the Cesium layer. In a 
DC gun this can be done inside the gun. The BINP experiment had a separate preparation chamber attached to the gun. The cathode could be retracted from the gun into this chamber.

In a SRF gun the preparation chamber must be separate from the gun. In our experiment the GaAs is soldered to the tip of a plug which is inserted into the back of the gun. A valve connected to the back of the gun allows access to the plug. As the valve needs to be open at cryogenic temperatures to avoid damage, the access pipe is also capped.

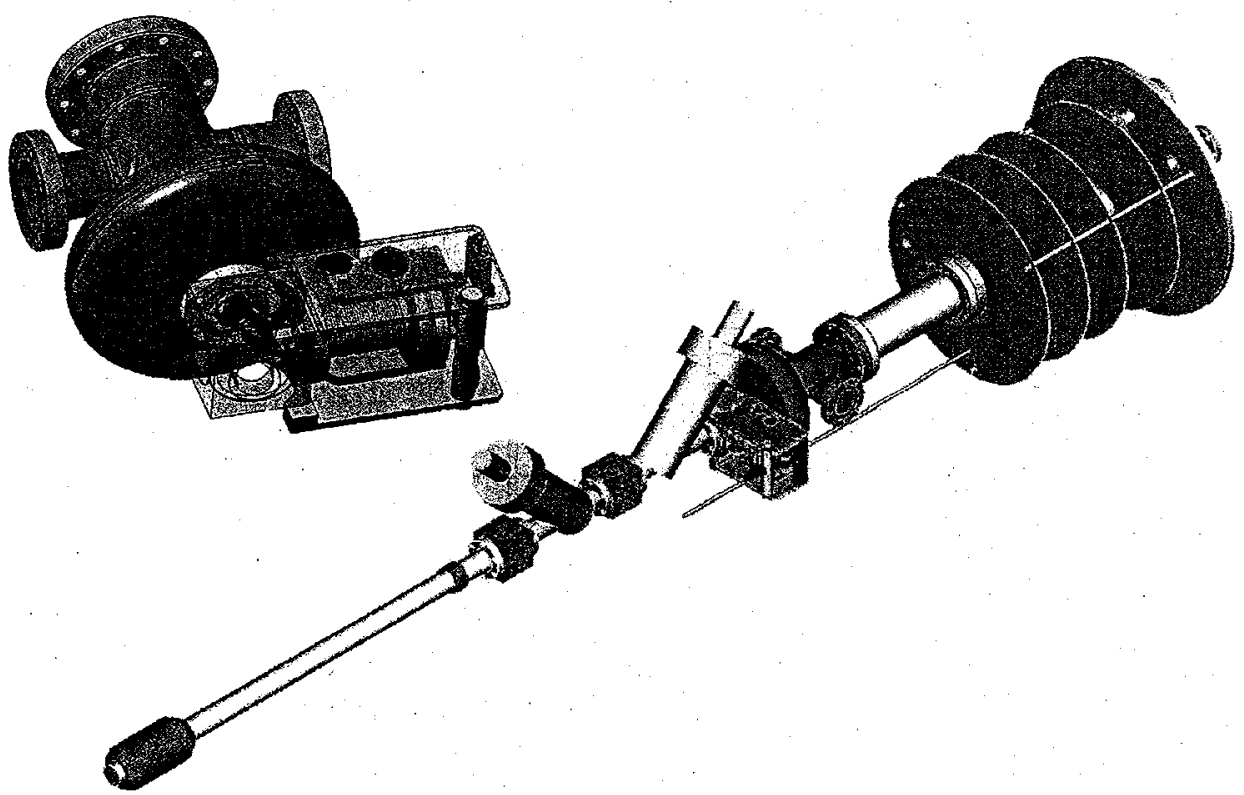

FIGURE 2. Gun assembly with attached cathode transporter. Also shown is the clam system that holds the plug in place during operation.

To remove the plug from the gun, the gun assembly is removed from the cryostat, the valve is closed and the cap is replaced by the "transporter" as shown in Figure 2. The corresponding valve on the transport is also closed, and the space between the valves is pumped down to $10^{-11}$ torr. Both valves are then opened.

The transporter uses a magnetically coupled actuator with bayonet connector to grab the cathode plug (Figure 3). The plug is then retracted into the transporter, the valves are closed and the transporter is disconnected from the gun.

In the same way, the transporter is then attached to the (separate) preparation chamber (Figure 4), where the plug is deposited for regeneration. Afterwards the plug is moved back into the gun in the same way, never leaving the ultra-high vacuum conditions.

The GaAs wafer is soldered to the tip of the plug and will have a diameter of $1 \mathrm{~mm}$. The cavity will be driven by an RF amplifier with 10 Watts output, restricting the electron beam current to $10 \mu \mathrm{A}$. The peak gradient will be $15 \mathrm{MV} / \mathrm{m}$, the beam energy at the exit of the gun will be about $0.8 \mathrm{MeV}$. 


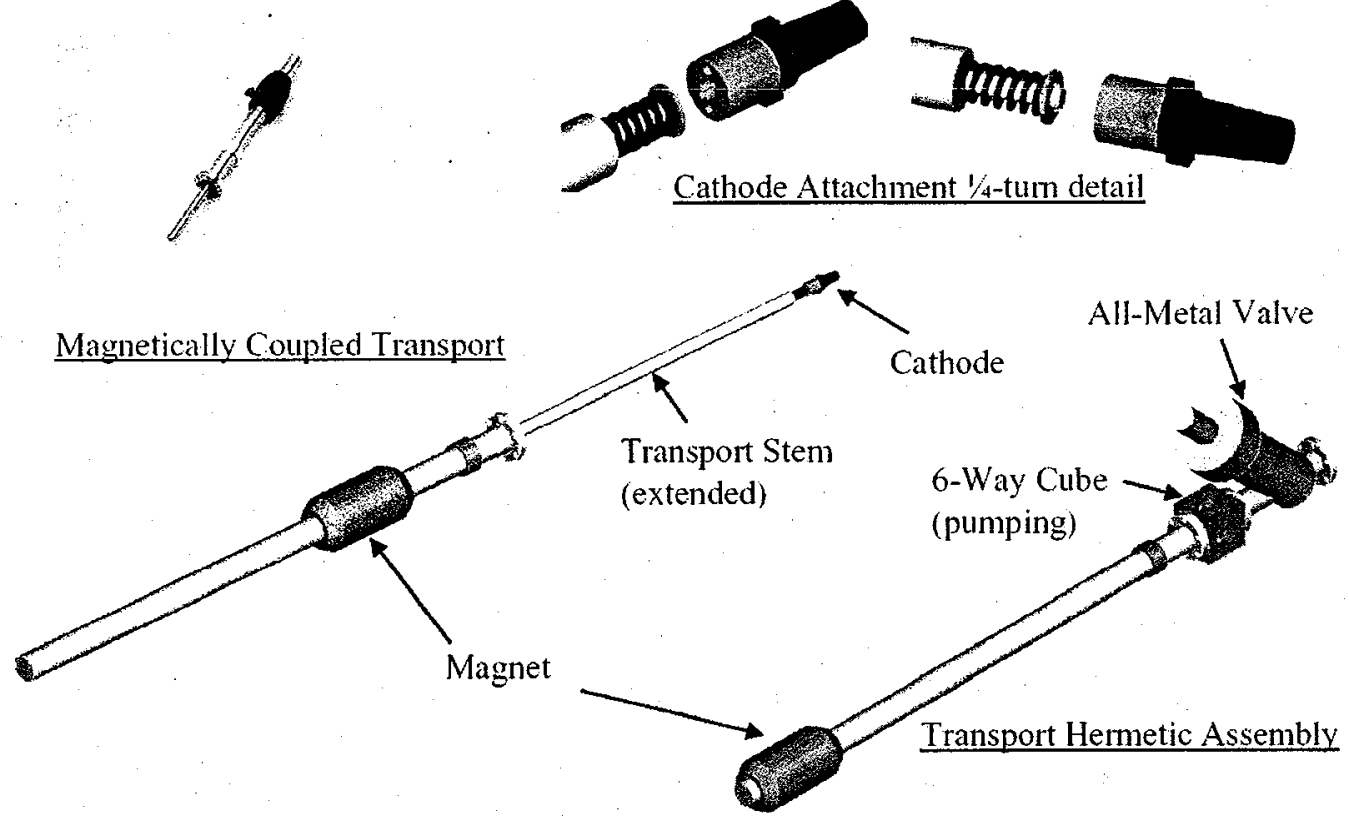

FIGURE 3. Cathode transporter with magnetically coupled actuator and bayonet attachment to the cathode plug.

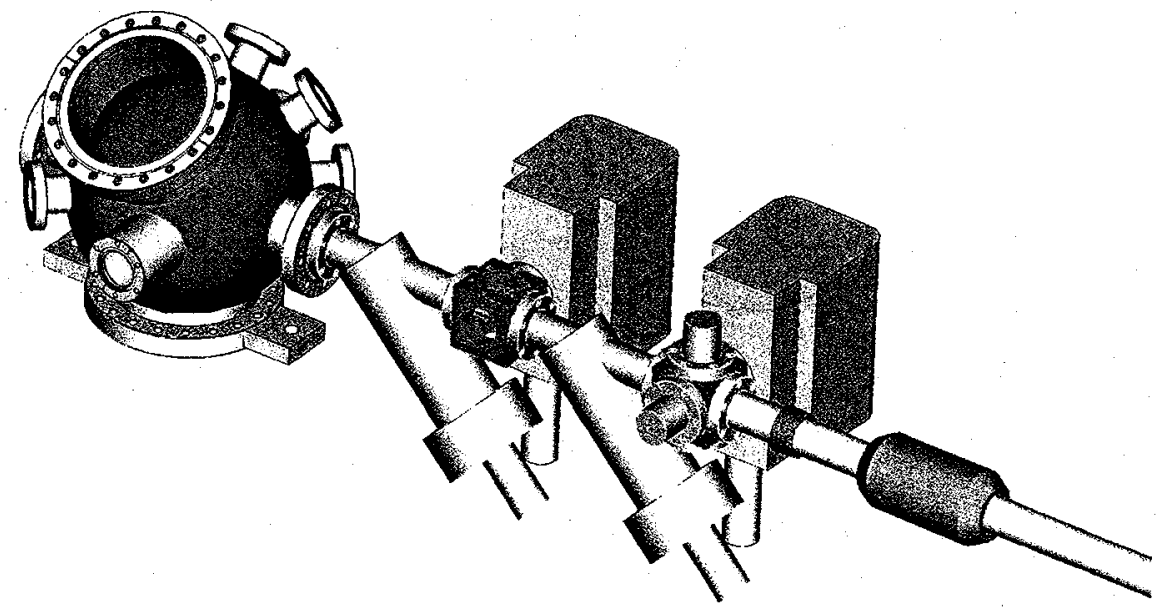

FIGURE 4. Cathode transporter connected to the preparation chamber. 


\section{STATUS OF THE PROJECT}

As of November 2007 the SRF gun and the cryostat have been tested, reaching a maximum gradient of $41 \mathrm{MV} / \mathrm{m}$. The next step is to modify the gun and install the plug receiver. This should be completed in the next six months. At the same time work on the preparation chamber is progressing. The experiment should be completed in 18 months.

\section{REFERENCES}

1. C.K.Sinclair, Very High Voltage Photoemission Electron Guns, Proc. PAC 2003, 76 (2003)

2. A.V.Aleksandrov, E.S.Konstantinov, P.V.Logatchov, A.V.Novokhatski, A.A.Starostenko, High Power Test of GaAs Photocathode in RF Gun, Proc. EPAC 98, (1998).

3. R. P. Fliller, H. Edwards, H. Bluem, J. Rathke, C.K. Sinclair, M. Huening, Progress on Using NEA Cathodes in an RF Gun, Proc. PAC 2005, (2005). 